\title{
ENHANCING THE EFFICIENCY OF IRAN KHODRO PERSONNEL THROUGH MODELLING THEIR IN-SERVICE TRAINING
}

\author{
Ramin Eftekhari ${ }^{1}$ \\ S. Ehsan Razavi ${ }^{2}$ \\ Elham Fariborzi ${ }^{3}$
}

\begin{abstract}
Today, authorities of organizations must contemplate the success and status of their units. An alternative to increasing the scientific growth of organizations is to provide inservice educational courses for the personnel. The current research aimed to present a model to improve the quality of the in-service training of Iran Khodro personnel. This was an applied research in terms of the objectives and descriptive-exploratory in terms of the methodology. Based on the theoretical framework of the research, organizational, individual, and educational factors were considered as the influential factors in improving the quality of in-service training for Iran Khodro personnel. A questionnaire was
\end{abstract}

applied to explain the model and collect the required data. The sample size was determined using the Cochran's formula, and the subjects were selected via simple random sampling. Data analysis was performed in SPSS and LISREL using descriptive and inferential statistics (confirmatory and exploratory factor analysis). According to the results of the descriptive statistics, the mean quality of in-service training and organizational, individual, and educational factors were estimated at $3.83,3.74,3.66$, and 3.45 , respectively. According to the inferential statistics using factor analysis, the obtained results indicated that the response categories raised in the research tool were organizational, individual, and educational factors. As such, the model

\footnotetext{
${ }^{1}$ Department of Educational Sciences,Mashhad Branch, Islamic Azad University, Mashhad, IRAN. Email:eftekhari.info@gmail.com

${ }^{2}$ Department of Electrical Engineering, Mashhad Branch, Islamic Azad University, Mashhad, IRAN. * Corresponding Author Email:ehsanrazavi@mshdiau.ac.ir ${ }^{3}$ Department of Educational Sciences, Mashhad Branch, Islamic Azad University, Mashhad, IRAN. Email:elhamfariborzi@gmail.com
} 
was developed to improve the quality of the in-service training of Iran Khodro Personnel based on the mentioned factors.

Keywords: Iran Khodro Personnel, Quality of In-service Training, Organizational Factors, Educational Factors, Individual Factors

\section{Introduction}

In-service training is an effective managerial tool to induce environmental changes and guarantee the provision of proper services, especially in public and governmental organizations. If in-service training is provided regularly and in a targeted manner to meet the needs of the staff, it not only improves the performance of the personnel and organizations, but it also could reinforce the skills of managers and promote client satisfaction (Carol, 2016). Undoubtedly, training is considered to be a reliable tool to enhance the quality of performance and for problem-solving in organizations, while its absence leads to numerous issues in organizations. The educational system of every organization should provide the employees with the necessary information, skills, and insights, so that they would be prepared
481

for the acquisition of various occupations. Therefore, training is considered to be major influential factor in educating the human resources of an organization and improve and exploitation of other organizational resources (Chaichi, 2012).

In the modern era, in-service training is indispensable for every organization and their human resources. Several organizations constantly design and provide educational courses for their staff regardless of their type and level of education. Such programs are mainly based on the dynamism in sciences and occupational needs. Moreover, investment in staff training has become widespread, and organizations are increasingly focusing on the development of their educational activities and provision of learning opportunities for staff at various organizational levels (Ebrahimi, 2013).

In the past two decades, special attention has been paid to employees as the largest and most valuable capital of organizations. Today, the rapid growth of information and occupational complications underscores the importance of staff training. According to Toffler, education is essential to the management of substantial changes in 
the future. In fact, effective education promotes the growth and abilities of individuals in their occupation, so that they could be more efficient. Evidently, higher knowledge of employees regarding their occupation results in more practical opinions and perceptions toward professional improvement (Jafari and Khezerloo, 2015: 95).

Studies similar to the current research play a key role in determining strengths and limitations from the perspective of the staff attending inservice training courses. As such, the increasing of knowledge is considered crucial as it provides proper opportunities to address and eliminate limitations.

Human resources are recognized as the foremost organizational assets in the evaluation of the resources and capabilities of organizations. This is due to the fact that humans are the largest and most active value-makers of institutions and organizations. The most prominent benefit of organizational and institutional investment in employees is the training of human resources. Such education enables human resources to acquire abilities, expand their capabilities, and learn the required skills (Daneshfard, 2009).

Planned education and training are provided on a regular basis by organizational managers to reinforce the competency of the organizational employees. In addition, employees must receive the necessary training to overcome the difficulties caused by rapid changes in the organizational environment and exploit their talents to help achieve organizational goals (Rimmer, 2015). On the other hand, the quality of such education is of paramount importance since low-quality education only wastes the time, energy, and resources of an organization (Carol, 2016).

The training and improvement of human resources are the key strategies of organizations for positive adaptation to change. The maintenance of every organization largely depends on the knowledge and skills of its employees, and the favorable status of these factors results in the higher adaptability of the organization with the changes in the environment (Sam Khanian, 2011: 13).

According to one of the definitions of in-service training, the essence of training is to increase the efficiency of employees and improving 
adaptation to the environment, which in turn enhance the quality of services in organizations and units. In-service training is merely an effort to improve knowledge and technical, occupational, and professional skills, as well as to establish desirable behaviors in the staff of an institution or organization and provide them with optimal duties and responsibilities (Chaichi, 2012: 14). From the perspective of Pierre and Gutter, in-service training is a form of systematic attraction, the main goal of which is to coordinate and align the aspirations, interests, and future needs of individuals with the needs and goals of the organization in the form of the expected performance of the staff (Fathi Vajargah, 2015).

Organizations are well aware of the importance of in-service training, and every organizational and institutional unit must allocate adequate time and assets to the training of the human resources depending on the status of the organization. In-service training must enable the continuous implementation of the planned courses, reinforcement of the skills and knowledge of the staff, problem-solving in the work environment, and assurance of survival of the organization. Constant efforts to improve the quality of in-service training could result in remarkable benefits (Ahmadi and Hakimi, 2009). The organizations that dedicate sufficient resources to the training of large human resources should ensure that the employees acquire the necessary skills in the provided training programs. As a result, such organizations succeed in maximizing their educational benefits (Hunge, 2018).

Scholars and researchers have proposed various models for staff education. For instance, the Parker model (2017) provides a map to pursue design and educational assessment. In this model, analysis of the needs leading to the development and determination of educational goals is the basis of designing educational programs and selecting appropriate teaching methods. It is also notable that the parker model is a multistage process based on a rotational context (Ayton, 2018: 8). Parker has presented various stages for this model, including the recognition of educational needs, determining educational goals, developing educational programs and methods, developing evaluation methods, and measuring the results of the selection, 
guidance, and leadership in staff training.

Another model that has been developed in this regard is based on organizational transformability, as well as some key principles. Accordingly, organizations must be dynamic and transformable, and education must be provided to maintain such dynamism. In addition, the model proposes that each occupation has a specific nature, and all occupations have a particular communication context; therefore, the abilities required for every occupation vary at different times (Al-hosseini, 2016: 77).

Another model proposed for staff education is the model of systematic approach to education, which emphasizes on the determining the educational goals and experiences of controlled learning to attain specific goals. In this model, feedback must also be assessed for the constant correction of the learning process. From this perspective, educational programs are never a finished product and are only matched to the information that is indicative achieving the ideal goals. On the other hand, this approach is used to recognize the complexities in the interactions between various components, providing an executive framework for the planning and pursuing goals. In this framework, it is essential to determine the programs that have proven effective in attaining organizational goals. Another prominent feature of this approach is providing a holistic view and a general set of interactions between subsystems (Goldstein, 2016: 21).

Since in-service training is discussed in the context of learning, the present study aimed to review various learning theories in this regard. There are numerous theories on learning methods, the most important of which are the stimulus-response school and Gestalt school. Furthermore, the social learning theory and facilitation are among the other prominent theories in this regard. The stimulus-response school is often recognized as the theory or school of behaviorists, revolving around the opinions of scientists who consider learning to be an opportunity to make a connection between a stimulus and a response. This theory allows animal testing and exploits various results regarding the learning methods used for humans, concluding that learning in humans occurs as a result of encouragement and punishment or reward and consequence (Defileps, 
2014: 180). For instance, Skinner believes that humans learn only if the behavior caused by learning results in receiving rewards. If an individual is introduced to pass an educational course, they may start learning when they are assured that passing the course and the subsequent improvement of their knowledge, skills, and behaviors will result in achieving spiritual and/or financial goals (Kreck, 2015: 19).

The Gestalt school greatly emphasizes on holism, and the followers believe that in order to improve the level of learning, various elements of a curriculum should encompass the subjects that are meaningful and relevant to the entire curriculum. In fact, these contents refer to the design and regulation of educational programs and organization of various educational courses.

The social learning theory emphasizes on the utmost importance of social relations and their impact on the learning of humans. Accordingly, anything that could be learned through direct experience could also be learned through direct observation, while humans cannot model their own observations (Wood, 2017: 40). Moreover, this theory recommends the use of educational aids (e.g., images and videos) as behavioral patterns.

Finally, the facilitation theory in learning emphasizes on the participation of learners in educational stages. Accordingly, the participants in educational courses are the vehicle of transferring behaviors, skills, and knowledge, which necessitates their participation in the learning process invariably. In this regard, experts, professors or educational instructors mostly act as the facilitator rather than a controller or presenter of educational contents (Abtahi, 2015: 199).

With regard to the provided contents and given the importance of inservice training courses, Iran Khodro Co. has aimed to hold educational courses to meet the educational needs of its human resources. In order to understand the effectiveness of these courses on improving the knowledge, skills, and favorable behaviors of human resources, level of goal realization in the courses, responsiveness of the education outputs to workplace needs, and illustrate the effectiveness of courses, it is essential to propose an appropriate pattern to enhance the quality of educational courses. With this background, the present study aimed to propose a proper 
model to improve the quality of the inservice training courses for Iran Khodro Personnel. Therefore, the main research question was as follows:

What is the most proper model for the improvement of the quality of the in-service training courses for the personnel of Iran Khodro Company?
486

The proposed model in the current research was used to identify the influential factors in the quality of the inservice training provided to Iran Khodro personnel. The model encompassed organizational, individual, and educational factors and was developed based on behavioral theories and Gestalt school.

\section{Research Model}

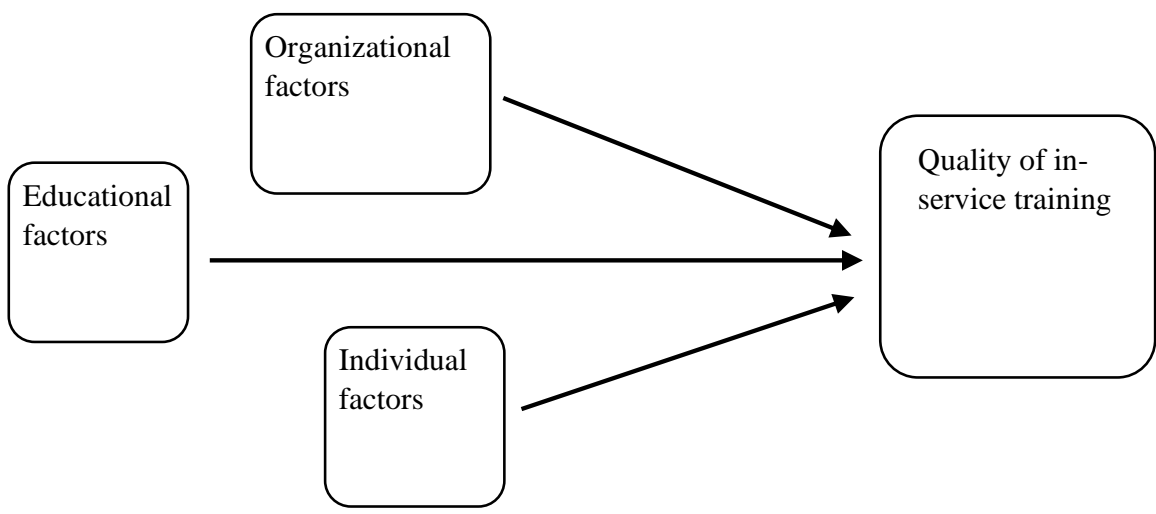

Figure 1. Conceptual Model of Research

\section{Research Questions}

The main research questions were as follows:

1. How is the quality of the in-service training provided to Iran Khodro personnel?

2. What are the influential factors in the improvement of the quality of the in-service training of Iran Khodro personnel?
3. What is the most proper pattern for the improvement of the quality of the in-service training courses provided to Iran Khodro personnel?

\section{Research Methodology}

This was an applied research in terms of the objectives since the obtained results could be used in Iran Khodro Company. In addition, the research was a survey in terms of classification based 
on the applied data collection method. The present study is an applied, descriptive-exploratory survey.

\section{Statistical Population and Samples}

The sample population of the present study included all the staff and personnel of Iran Khodro Company who attended and completed the provided inservice training courses. In total, Iran Khodro has 4,000 employees, 2,200 of whom had a history of attending inservice training courses. The sample size was estimated at 277 using the Cochran's formula. The participants were selected via simple random sampling based on the accessibility of the personnel's names.

\section{Data Collection Tools}

Data were collected using a researcher-made questionnaire consisting of two question sets. The first set (coded with alphabetical letters) was developed to determine the demographic characteristics of the participants, including age, gender, marital status, education level, and history of activity. The second set had two sections, which were developed to address the research questions. The first section included items regarding the influential factors in the improvement of the quality of in- service training courses, and the second section contained items regarding the assessment of the quality of the inservice training courses for Iran Khodro personnel. The face and content validity of the questionnaire were assessed, and its reliability was determined based on the Cronbach's alpha.

\section{Data Analysis}

Data analysis was performed in SPSS and LISREL using descriptive and inferential statistics. Initially, exploratory factor analysis was used to index and classify the response categories regarding the improvement of the quality of in-service training. Confirmatory factor analysis was applied after determining the dimensions and indices to approve or reject the dimensions. Ultimately, we designed a proper model for the improvement of the quality of the in-service training courses provided to Iran Khodro personnel.

\section{Reliability and Validity of the}

\section{Research Instrument}

The research instrument was evaluated in terms of face validity and content validity. After the assessment of the tool by professors and applying their comments, the questionnaire was 
evaluated in terms of the contents to ensure that it could efficiently cover the conceptual dimensions of the study variables. Furthermore, the reliability of the tool was determined based on the Cronbach's alpha, the results of which were indicative of the internal consistency of the items of the research instrument. The Cronbach's alpha was estimated to be $>0.7$ for all the items of the questionnaire.

\section{Descriptive Results}

Table 1. Descriptive Statistics Regarding Research Variables

\begin{tabular}{cccccccc}
\hline & $\begin{array}{r}\text { Averag } \\
\text { e }\end{array}$ & Media & Mode & $\begin{array}{c}\text { Standard } \\
\text { deviation }\end{array}$ & & & Skewness Highest Lowest \\
\hline $\begin{array}{c}\text { Quality of In- } \\
\text { service Training }\end{array}$ & 3.83 & 4,00 & 4.25 & 0.63 & -0.76 & 5.00 & 1.90 \\
\hline $\begin{array}{c}\text { Organizational } \\
\text { Factors }\end{array}$ & 3.74 & 3.65 & 3.60 & 0.44 & -0.04 & 4.60 & 2.80 \\
\hline $\begin{array}{c}\text { Individual } \\
\text { Factors }\end{array}$ & 3.66 & 3.60 & 3.00 & 0.57 & 0.21 & 5.00 & 2.80 \\
\hline $\begin{array}{c}\text { Educational } \\
\text { Factors }\end{array}$ & 3.45 & 3.60 & 2.40 & 0.83 & -0.34 & 4.80 & 1.80 \\
\hline
\end{tabular}

Table 1 shows the descriptive results obtained in the study (mean, median, and standard deviation), as well as the maximum and minimum values of the study variables. According to the information in this table, the mean quality of the in-service training of Iran Khodro personnel was 3.83 (range: 1-5).
Table 1 contains the statistics regarding the other study variables.

\section{Inferential Results}

The problem of the normal distribution of data on study variables may not be important in large sample sizes since they neutralize the bias effect caused by the non-normal distribution of 
the data. As such, prerequisite tests were initially performed in the present study for data analysis, and the results regarding the normal distribution of the collected data are presented in Table 2. The normality test results demonstrated the normal distribution of the data on all the research variables.

Table 2. Results of Kolmogorov-Smirnov Test on Normal Distribution of Data

\begin{tabular}{ccccc}
\hline Variables & $\begin{array}{c}\text { Number of } \\
\text { Data }\end{array}$ & $\begin{array}{c}\text { Kolmogorov- } \\
\text { Smirnov test }\end{array}$ & P-value & $\begin{array}{c}\text { Result } \\
\text { (normal/non- } \\
\text { normal } \\
\text { distribution) }\end{array}$ \\
\hline $\begin{array}{c}\text { Quality of In- } \\
\text { service Training }\end{array}$ & 277 & 1.148 & 0.152 & Normal \\
\hline $\begin{array}{c}\text { Organizational } \\
\text { Factors }\end{array}$ & 277 & 1.321 & 0.084 & Normal \\
\hline $\begin{array}{c}\text { Individual Factors } \\
\text { Educational Factors }\end{array}$ & 277 & 1.365 & 0.059 & Normal \\
\hline
\end{tabular}

\section{Response to the First Research Question}

$Q$ 1: How is the quality of the in-service training courses for Iran Khodro Personnel?

The mean quality of in-service training was estimated to be 3.83 based on the applied questionnaire, which was higher than the mean of the variable with a significant difference $(\mathrm{P}=0.05)$ according to the results of t-test.
According to the information in Table 3, the significance level of single-group ttest was 0.000 at the two-domain significance level, which was lower than the minimum significance level of 0.05 and equal to 7.826 based on the $\mathrm{t}$ value. In addition, the value was higher than the critical $t$ value (1.9673) at the significance level of 0.95 and degree of freedom of 276.

Table 3. Results of Single-sample T-test on Quality of In-service Training of Iran Khodro Personnel 


\begin{tabular}{ccccccc}
\hline \multirow{2}{*}{$\begin{array}{c}\text { Component } \\
\text { in Current } \\
\text { Status }\end{array}$} & $\mathbf{T}$ & $\begin{array}{c}\text { Degree of } \\
\text { Freedom }\end{array}$ & $\begin{array}{c}\text { Difference } \\
\text { from Mean }\end{array}$ & $\begin{array}{c}\text { Level of } \\
\text { Significance }\end{array}$ & $\begin{array}{c}\text { Lower } \\
\text { Bound }\end{array}$ & $\begin{array}{c}\text { Upper } \\
\text { bound }\end{array}$ \\
\cline { 2 - 7 } Quality of & & & & & & \multicolumn{2}{c}{$\begin{array}{c}\text { Confidence } \\
\text { In-service }\end{array}$} & 7.826 & 276 & 0.8341 & 0.000 & 0.1367 & 0.2762 \\
Training & & & & & & \\
\hline
\end{tabular}

Based on these findings, the $\mathrm{H} 0$ hypothesis was rejected, and the $\mathrm{H} 1$ hypothesis was accepted, confirming that the quality of in-service training for Iran Khodro personnel was above average.

\section{Response to the Second Research Question}

$Q$ 2: What are the influential factors in the quality of the in-service training of Iran Khodro personnel?

To address this question, exploratory factor analysis was used. Initially, the reliability of the scale and each of its items was investigated. After eliminating the items with the correlation of less than 0.3 , the factor structure of the scale was assessed using exploratory factor analysis, the results of which are discussed in the following sections.

\section{Sampling Sufficiency Test}

Since the Kaiser-Mayer-Olkin (KMO) index was 0.810 (appropriate index: $>0.6$ ), the number of the statistical samples for factor analysis was considered sufficient. In addition, the significance level of Bartlett's test was less than $0.05 \%$, which indicated that the factor analysis was proper for the identification of the structure of the factor model.

Table 4. Results of Sampling Sufficiency Test

\begin{tabular}{cc}
\hline KMO Index & 0.810 \\
\hline Bartlett's Test & 762.523 \\
\hline Degree of Freedom & 276 \\
\hline Significance Level & 0.000 \\
\hline
\end{tabular}




\section{Shared Extraction Test}

Table 5 shows the extraction of the agents in order to show the explanation levels of the variances of the questionnaire items. At this stage, the factors with the extraction subscriptions of less than 0.5 were eliminated since these values demonstrated that the agent had no correlations with the factors. This stage continued until the extraction values exceeded 0.5 .

Table 5. Results of Shared Extraction

\begin{tabular}{|c|c|c|c|c|c|}
\hline $\begin{array}{c}\text { Shared } \\
\text { Extraction }\end{array}$ & Factors & $\begin{array}{c}\text { Shared } \\
\text { Extraction }\end{array}$ & Factors & $\begin{array}{c}\text { Shared } \\
\text { Extraction }\end{array}$ & Factors \\
\hline 0.840 & 28 & 0.814 & 15 & 0.921 & 1 \\
\hline 0.687 & 29 & 0.652 & 16 & 0.897 & 2 \\
\hline 0.921 & 30 & 0.908 & 17 & 0.899 & 3 \\
\hline 0.899 & 31 & 0.797 & 18 & 0.891 & 4 \\
\hline 0.886 & 32 & 0.692 & 19 & 0.879 & 5 \\
\hline 0.891 & 33 & 0.688 & 20 & 0.889 & 6 \\
\hline 0.879 & 34 & 0.768 & 21 & 0.634 & 7 \\
\hline 0.889 & 35 & 0.744 & 22 & 0.784 & 8 \\
\hline 0.896 & 36 & 0.908 & 23 & 0.896 & 9 \\
\hline 0.874 & 37 & 0.466 & 24 & 0.744 & 10 \\
\hline 0.881 & 38 & 0.772 & 25 & 0.932 & 11 \\
\hline 0.766 & 39 & 0.824 & 26 & 0.932 & 12 \\
\hline 0.932 & 40 & 0.466 & 27 & 0.892 & 13 \\
\hline & & & & 0.652 & 14 \\
\hline
\end{tabular}

According to the obtained results, the shared extraction of the factors that was less than 0.5 was eliminated. In addition, the factors with the shared extraction subset of less than 0.5 (items 24 and 27) were eliminated.

\section{Explaining of the Variance}

The third stage of exploratory factor analysis was performed to 
determine the factors that remained in the analysis. Table 6 shows the number of the identified factors and degree of variance variation in each factor. According to the output derived from the software analysis, it could be stated that the first three factors had special vectors of larger than one and remained in the model

Table 6. Variance Explanation

\begin{tabular}{ccccccc}
\hline $\begin{array}{c}\text { Special Values of Extraction } \\
\text { Factor by Rotation }\end{array}$ & \multicolumn{3}{c}{ Special Values } & Categories \\
\hline $\begin{array}{c}\text { Cumulative Variance } \\
\text { Percentage }\end{array}$ & Percentage & Total & $\begin{array}{c}\text { Cumulative } \\
\text { Percentage }\end{array}$ & $\begin{array}{c}\text { Variance } \\
\text { Percentage }\end{array}$ & Total & \\
\hline 45.329 & 45.329 & $\begin{array}{c}13.43 \\
2\end{array}$ & 45.329 & 45.329 & 13.432 & 1 \\
\hline 58.513 & 13.185 & 2.537 & 58.513 & 13.185 & 2.537 & 2 \\
\hline 67.262 & 9.749 & 2.402 & 67.262 & 9.749 & 2.402 & 3 \\
\hline
\end{tabular}

According to the information in

Table 6, three factors had specific vectors of larger than one, and the first, second, and third factor could explain approximately $45 \%, 13 \%$, and $9 \%$ of the variance, respectively. In addition, the cumulative variance was estimated at $67.262 \%$, indicating that these factors explained $67 \%$ of the variance of the research questions.

\section{Cumulative variance} explanation should be higher than $60 \%$. According to the results of the rotational matrix, the first factor was based on categories $1,3,4,5,6,7,9,11,12$, and
13 and referred to as organizational factors. The second factor was based on categories 14, 16, 17, 18, 19, 21, 22, 23, 25,26 , and 28 and referred to as educational factors based on the theoretical foundations of the research. The third factor was based on categories 29, 30, 31, and 33 and referred to as individual factors based on the theoretical foundations of the research.

\section{Response to the Third Research Question}

$Q$ 3: What is the most proper model for the improvement of the quality 
of the in-service training of Iran Khodro personnel?

To address the third research question, confirmatory factor analysis was used in the LISREL software. This analysis was also applied in order to confirm the factor structure and power and significance test of each variable in the scale of the appropriate model for improving the quality of the in-service training of Iran-Khodro personnel (diagrams $1 \& 2$ ).

According to the secondary factor analysis, all the paths were significant with the verbal accuracy probability of $95 \%$. Table 7 shows the results regarding the examination of the
493

effects of the endogenous latent variables on the observed variables. As is presented in this table, items one, 14, 29, and 34 in the questionnaire were considered as the constant scale variable in the measurements, and the $\mathrm{t}$ values were not reported.

According to the information in Table 7, the estimated coefficients of all the paths were significant. In addition, the values of the standardized parameter for each observed variable (indicator) represented the factor load power on the factor (non-variable), and the $t$ values of more than 1.97 indicated the significance of this contribution.

Table 7. Effects of Endogenous Latent Variables on Observed Variables Y) y $\lambda$ ، LAMBDA-Y

\begin{tabular}{ccccc}
\hline $\begin{array}{c}\text { Parameter } \\
\text { Items/Factors }\end{array}$ & $\begin{array}{c}\text { Estimation of } \\
\boldsymbol{b} \text { Parameter }\end{array}$ & $\begin{array}{c}\text { Standard } \\
\text { Error }\end{array}$ & $\begin{array}{c}\text { Standardized } \\
\text { Parameter }\end{array}$ & t \\
\hline Question 21 & 0.5 & Individual Factors & & - \\
\hline Question 22 & 0.6 & 0.7 & 0.61 & 8.19 \\
\hline Question 23 & 0.7 & 0.57 & 0.70 & 7.88 \\
\hline Question 24 & 0.8 & 0.37 & 0.67 & 8.98 \\
\hline Question 25 & 0.49 & 0.72 & 0.57 & 7.25 \\
\hline Question 26 & 0.48 & 0.49 & 0.60 & 7.18 \\
\hline Question 27 & 0.56 & 0.36 & 0.57 & 7.11 \\
\hline Question 28 & 0.73 & 0.44 & 0.82 & 8.77 \\
\hline
\end{tabular}


Periódico do Núcleo de Estudos e Pesquisas sobre Gênero e Direito Centro de Ciências Jurídicas - Universidade Federal da Paraíba V. 8 - $\mathrm{N}^{\circ} 05$ - Ano 2019

ISSN | 2179-7137 | http://periodicos.ufpb.br/ojs2/index.php/ged/index

\begin{tabular}{|c|c|c|c|c|}
\hline & & & & 49 \\
\hline Question 29 & 0.59 & 0.66 & 0.60 & 6.33 \\
\hline Question 30 & 0.50 & 0.68 & 0.61 & 7.63 \\
\hline Question 31 & 0.55 & 0.49 & 0.76 & 8.85 \\
\hline Question 32 & 0.66 & 0.68 & 0.62 & 7.70 \\
\hline Question 33 & 0.45 & 0.57 & 0.61 & 7.66 \\
\hline Question 34 & 0.57 & 0.57 & 0.67 & 8.03 \\
\hline \multicolumn{5}{|c|}{ organizational factors } \\
\hline Question 14 & 0.62 & 0.69 & 0.68 & - \\
\hline Question 15 & 0.41 & 0.74 & 0.54 & 8.21 \\
\hline Question 16 & 0.41 & 0.86 & 0.44 & 5.41 \\
\hline Question 17 & 0.55 & 0.61 & 0.68 & 7.26 \\
\hline Question 18 & 0.54 & 0.58 & 0.67 & 7.19 \\
\hline Question 19 & 0.58 & 0.57 & 0.69 & 7.31 \\
\hline Question 1 & 0.53 & 0.63 & 0.65 & 7.64 \\
\hline Question 2 & 0.55 & 0.47 & 0.72 & 8.18 \\
\hline Question 3 & 0.50 & 0.55 & 0.71 & 6.99 \\
\hline Question 4 & 0.63 & 0.44 & 0.81 & 9.52 \\
\hline Question 5 & 0.36 & 0.78 & 0.53 & 6.95 \\
\hline Question 6 & 0.39 & 0.75 & 0.55 & 7.31 \\
\hline Question 7 & 0.76 & 0.32 & 0.80 & 9.40 \\
\hline Question 8 & 0.51 & 0.70 & 0.57 & 7.69 \\
\hline Question 9 & 0.70 & 0.57 & 0.65 & 7.57 \\
\hline
\end{tabular}

Educational Factors

\begin{tabular}{ccccc}
\hline Question 11 & 0.56 & 0.56 & 0.67 & - \\
\hline Question 12 & 0.46 & 0.69 & 0.65 & 6.69 \\
\hline Question 13 & 0.48 & 0.65 & 0.58 & 6.89 \\
\hline Question 36 & 0.55 & 0.49 & 0.76 & 7.35 \\
\hline Question 37 & 0.33 & 0.91 & 0.30 & 8.82 \\
\hline Question 38 & 0.58 & 0.72 & 0.53 & 3.73 \\
\hline Question 39 & 0.77 & 0.54 & 0.68 & 3.90
\end{tabular}


Question 40

Table 8 shows the effects of exogenous latent variables (i.e., influential factors in the improvement of the quality of the in-service training of
Iran Khodro personnel) on the endogenous latent variables (organizational, individual, and educational factors).

Table 8. Effects of Exogenous Latent Variables (KSI, $\xi$ ) on Endogenous Latent Variables (ETA, $\eta)$

\begin{tabular}{lllc}
\hline \multicolumn{1}{c}{ Direction } & $\begin{array}{c}\text { Estimation } \\
\text { of Parameter }\end{array}$ & $\begin{array}{c}\text { Standardized } \boldsymbol{b} \\
\text { Parameter }\end{array}$ & t \\
\hline \multicolumn{2}{c}{ Influential factors in improvement of quality of in-service training of Iran } \\
& Khodro personnel & \\
\hline Individual Factors & 0.56 & 0.56 & 6.46 \\
\hline Organizational Factors & 0.89 & 0.89 & 8.73 \\
\hline Educational Factors & 0.81 & 0.81 & 7.43 \\
\hline
\end{tabular}

The $t$ value confirmed the effects of the influential factors in the quality of the in-service training of Iran Khodro personnel. In other words, the organizational, individual, and educational factors were significant with the possible speech accuracy of $95 \%$.

Table 9 shows the goodness of fit index of the model based on 


\begin{tabular}{ccccc}
\hline Chi-square & $\begin{array}{c}\text { Degree of } \\
\text { Freedom }\end{array}$ & $\begin{array}{c}\text { Level of } \\
\text { Significance }\end{array}$ & $\begin{array}{c}\text { Root Mean Error of } \\
\text { Approximation } \\
\text { Squares }\end{array}$ & $\begin{array}{c}\text { Goodness of } \\
\text { Fit Index }\end{array}$ \\
\hline 1354.73 & 261 & 0.000 & 0.060 & 0.95 \\
\hline
\end{tabular}

Chi-square statistics are considered to be the most important fitness statistic, which measures the difference between the observed and estimated matrices. The insignificance of this statistic indicates the fitting of the model with the data, while a disadvantage of this statistic is that it is susceptible to sample size, and its lack of significance decreases in large samples sizes.

The value of less than 0.08 for the root index of the mean error of approximation squares and values more than 0.9 for the goodness of fit and modified goodness of fit indices were considered as the criteria for conformance to the observed pattern. As a result of the identified model, the influential factors in improving the quality of the in-service training of IranKhodro personnel were confirmed by the organizational factors, individual factors, and educational factors.

\section{Discussion and Conclusion}

Technological advancement has changes the styles and methods of organizations, and change invariably requires the acquisition of new knowledge and skills. The quantitative and qualitative level of organizational changes might be intimidating to managers and staffs, making them assume there are no opportunities and ability to adapt to these changes. Therefore, it should be admitted that the life of organizations largely depends on the acquisition of new knowledge and skills. If the knowledge and skills of staff are in line with the needs of the community, scientific advancement, and technological changes, confidence in the success of the organization increases in the individuals and organizations.

Some of the key factors that are involved in novelty and knowledge acquisition are individual growth, motivation, expertise, personal perfection, and avoidance of stagnation. Organizational development is the foundation for organizational improvement, which is defined as the 
improvement of human resources. Human resource training is a reliable approach to the improvement of human resources in organizations, which is implemented in various forms prior to recruitment, as in-service courses or during service (Mousavi, 2015: 5).

Considering the new issue of inservice training and the need to pay special attention to the influential factors in the life of organizations, knowledge regarding the quality of in-service training and, more importantly, finding the association between this concept and the other influential variables in this regard are considered essential. As such, the current research aimed to address three key questions.

According to the obtained results, the mean dependent variable (i.e., quality of the in-service training of Iran Khodro personnel) was 3.83 (range: 1-5). The mean values obtained for organizational factors, individual factors, and educational factors were $3.74,3.66$, and 3.45, respectively (range: 1-5). The inferential findings regarding the responses to the research questions are discussed in the following paragraphs.
$Q$ 1: How is the quality of the in-service training of Iran Khodro personnel?

We attempted to address this question using single group t-test, and the results indicated that the quality of the in-service training of Iran Khodro personnel was above average (3).

$Q$ 2: What are the influential factors in the improvement of the quality of the in-service training of Iran Khodro personnel?

Exploratory factor analysis was used to respond to this question. According to the obtained results, three factors with specific vectors were larger than one, and the first, second, and third factor could explain $45 \%, 13 \%$, and $9 \%$ of the variance, respectively. In addition, the cumulative variance was estimated at $67.26 \%$, indicating that the three factors could explain almost $67 \%$ of the variance of the research questions.

$Q$ 3: What is the most proper model for improving the quality of the inservice training of Iran Khodro personnel?

The results of factor analysis indicated that organizational factors, educational factors, and individual factors were effective in improving the 
quality of the in-service training provided to the staff of Iran Khodro.

Our findings are in line with the results obtained by Bazargan (2006), who evaluated the effectiveness of the in-service education of organizational managers and education and research management planning in Tehran province (Iran) from the perspective of the participants. According the findings, in-service training enhanced the skills and knowledge of the employees.

The results of the present study are also consistent with the results obtained by Jamalvandi (2009) and Ebrahimpour (2009). Accordingly, the satisfaction of the staff participating in training courses was correlated with the type of provision and management of time and place. The proportionality of the course with their occupational needs was moderate and high, while the use of educational technology was at a low level, with the staff of the courses preferring purely theoretical courses.

According to the results of the present study, the factors of lesson plan, method of education, interpersonal relations, scientific and continuous evaluation, needs of the learners, encouragement of the learners, and supervising the educational process were also influential in improving the quality of in-service training. In this regard, Ebrahimi (2013) assessed the influential factors in the promotion of the quality of in-service training from the perspective of the employees in District 9 Gas Transmission Operations (Tehran, Iran), and the obtained results are in congruence with the findings of the current research. According to the mentioned study, there were significant correlations between human, support, and management factors and the quality of in-service training. Among the mentioned influential factors in the quality of in-service training, the human factors had the most significant impact, while the management factors had the least significant effect on the quality variable. However, the results of the mentioned study were inconsistent with the current research in terms of the prioritization of the influential factors in the quality of in-service training. This discrepancy could be due to the differences in the sample populations of the studies as differences between organizations could yield variable results in scientific research structurally.

According to the results of the present study, organizational factors were among the most significant 
influential factors in the quality of inservice training. Therefore, it is recommended that the managers of Iran Khodro Company provide the necessary equipment for the provision of new learning opportunities in the workplace, which will in turn result in a flexible organizational structure for the use of inservice training, as well as the empowerment of the employees, practice of using new learning, provision of information technology infrastructures for effective learning by the staff, flexible leadership styles in the workplace so as to speed up the use of new training by personnel, easy access of the employees to the required information and a proper work environment for the use of new schools by the authorities of Iran Khodro.

With regard to the educational factors, it is recommended that the managers of the company provide a balance between their activities, measures, and training programs with the tasks if the personnel and pay special attention to the justification of the staff regarding the educational contents, evaluating the awareness of the course instructors about the use of the training contents in the workplace by the employees, usefulness of the training in improving the working conditions of the staff, similarity of various activities, establishing assignments and training sessions with activities, access to comprehensive educational contents in proportion to the needs of the employees, relevance of training to organizational needs, and providing information to the employees regarding their expectations of the training course.

With respect to the individual factors, it is recommended that Iran Khodro personnel take measures in order to create a sense of individual responsibility to attend the provided training courses, as well as toward their colleagues in order to encourage their participation in the training courses and use new learning contents. Furthermore, the employees should make individual effort and desire to change their working methods in accordance with the received training during the course and establish interactive relations among the participants of the course in order to encourage colleagues to attend the training courses and help their colleagues with problem-solving using the new learning contents in the work environment. It is expected that Iran Khodro experience significant changes 
in the quality of their in-service training based on our findings.

\section{References}

Carol P, Demands FD. Continuous Quality Improvement: Integration Best Practice in to Teacher Education. The Journal of Educational Management. 2016; 211(9): 2-4.

Chaichi P. Methods of In-service Training, Tehran: Agah Publications. 2012.

Ebrahimi S.H. The Role and Effect of Factors Affecting the Quality of Inservice Training Courses from the Viewpoint of Employees in District 9 of Tehran Transmission Operations. The First Virtual Conference on Education . 2013.

Jafari M, Khazarlou J. Evaluation of Effect of Physical Space on the Quality of Learning (Education) of Students of Valiasr Education Center of Tabriz. Quarterly Journal of Law Enforcement Studies. 2015; 35: 1-20.
Daneshfard K. Calendar of Short-term

Educations in Islamic Azad University. Reading Office. 2009; 36-50.(in Persian)

Reamers E. Teacher Professional Development: An International Review of Literature. Paris, UN publication. 2015.

Khanian S, Rabi M. Human Resource Education Planning (Foundations and Processes). Tehran: Mehr Borna Publications. 20011.

Fathi Vajargah K. Planning of In-service Training of Employees. Tehran: Samt Publications . 2015.

Hunge T. The relation of training practices and organizational performance in the Medium Enterprise. Journal of Education and Traning.2018; 5(8-9): 44-437.

Ayton J.E. In Cervices Training For Teacher in Nzo schwa aces in Organizations (3rd). New Jersey: Prentice Hall. 2018.

Al-Hosseini H. The Theory of Continuous Engineering of C.E.O Organization (Explaining the Originality 
of Permanent Change in the Structure of

Organizations as Field of Individual and

Social Development), Bandar Abbas:

University of Hormozgan . 2016.

Goldstein V.S. The Impact of TPACK

pre-service teacher confidence in embedding ICT in to curriculum areas.

Education Technology Research

Development. 2016; 55: 547-572.

Defileps L, Wise L. The role of tutors in facilitating online student engagement. Wrest Point. Hobart Tasmania Australia. Proceedings ascilite 2011 Hobart:

Concise Paper. 2014.

Kreck M.H. Discussing teaching videocassette online: Perspectives of pre service and in-service EFL teachers in Taiwan. Computers \& Education.2015; 59(1):120-133.

Wood hall M. Cost-Benefit Analysis in Education planning. Paris: UNESCO/IIEP.2017.

Abtahi H. Human Resources Training and Development. 2nd Edition, Tehran, Sazman-e Gostaresh Institute for Education Planning and Studies .2015 